\title{
LA AVENTURA EUROPEA DEL EPIDENDRUM RADICANS
}

\author{
Carlos Ossenbach S. \\ Fundación Charles H. Lankester \\ Sabanilla de Montes de Oca, Costa Rica. caossenb@racsa.co.cr
}

El 2 de noviembre de 1803, a bordo de la corbeta "Zeballos", arribaron al puerto de Cádiz 27 cajones que contenían gran parte del material colectado durante 16 años por la Real Expedición Botánica a Nueva España. Desde 1786, y bajo la dirección de Martín de Sessé y José M. Mociño, esta expedición había recorrido y explorado las tierras del Virreinato de Nueva España, incluyendo las de la Capitanía General de Guatemala y las Islas de Barlovento.

Encerrado en uno de estos cajones, o en los que la expedición había enviado previamente desde México, se encontraban al menos cuatro ejemplares herborizados de una especie de orquídea que aún no había sido bautizada. Faltaban todavía 28 años para que, después de muchas peripecias, uno de dichos ejemplares llegara a manos de John Lindley, quien la describiría por primera vez para la ciencia en su Genera and Species of Orchidaceous Plants en 1831, con el nombre de Epidendrum radicans Pav. ex Lindl.

El primer ejemplar de E. radicans que conocemos de Costa Rica lo colectó el alemán Hermann Wendland en Cartago en 1856, y es Hemsley en su Biologia Centrali-Americana (1886-1888) el primero en mencionarla de nuestro país. Epidendrum radicans es sin duda la más común de las orquídeas de Costa Rica, donde se adapta a casi cualquier terreno y clima. Así, la encontramos en la península de Osa y en la cordillera de Talamanca, en Guanacaste y en Sarapiquí. Su sitio preferido son, sin embargo, las zonas intermedias entre 1000 y 1400 m de elevación.

La siguiente es la descripción original de Lindley:

\section{EPIDENDREAE}

\section{b. Labello bilobo}

35. EPIDENDRum radicans. Pavon. Mss.

E. foliis distichis cordatis ovatis obtusis, caule simplici apice aphyllo vaginato, sepalis petalisque lanceolatis acutis patentibus, labello bipartito laciniis subcuneatis deflexis fimbriatis basi bicalloso.

Hab. in Mexico; Pavon. (exam. s. sp. in Herb. Lambert.) Facies E. elongati. Caulis radices longissimas albas simplices promens.
La nota "Hab. in Mexico; Pavon. (exam. s. sp. in Herb. Lambert.)" es la que despertó nuestra curiosidad, ya que encierra misterios y aparentes contradicciones.

José Pavón había dirigido, junto a Hipólito Ruiz, la Real Expedición Botánica a Perú y Chile (17771788), pero nunca estuvo en México. ¿Por qué, entonces, menciona Lindley a Pavón junto a una orquídea aparentemente colectada en México? Y, ¿quiénes eran Lambert y su herbario?

En 1570, Francisco Hernández había sido enviado por el rey Felipe II para estudiar las plantas medicinales y todo lo referente a la historia natural de México. Hernández escribió una "Historia Natural de Nueva España”, que desapareció en 1761 en el incendio de El Escorial. Sin embargo, pudieron recuperarse cinco volúmenes manuscritos en la biblioteca del Colegio Imperial de Madrid, cuya publicación fue aprobada en 1874.

Entretanto, desde Cuba, donde ejercía su profesión como cirujano en la escuadra del Marqués de Socorro, el médico español Martín de Sessé propuso, en enero de 1875, a Casimiro Gómez Ortega, director del Real Jardín Botánico de Madrid, la idea de establecer un jardín y una cátedra de botánica en la capital mexicana. La idea de completar la publicación de la obra de Hernández con documentos y dibujos (duplicados) que pudieran encontrarse en México y la oportuna propuesta de Sessé dieron motivo a la promulgación por el rey Carlos III de la Real Orden de 27 de octubre de 1786. En ella se ordena establecer en Nueva España el Jardín Botánico, la Cátedra de Botánica (primera en América) y la formación de una expedición que debía "formar los dibujos, recoger las producciones naturales e ilustrar y completar los escritos de Francisco Hernández".

En mayo de 1788 se inauguraron el Jardín y la Cátedra de Botánica en México. Poco tiempo más tarde, en el segundo curso de botánica, en 1789, destacó un brillante alumno que posteriormente ten- 


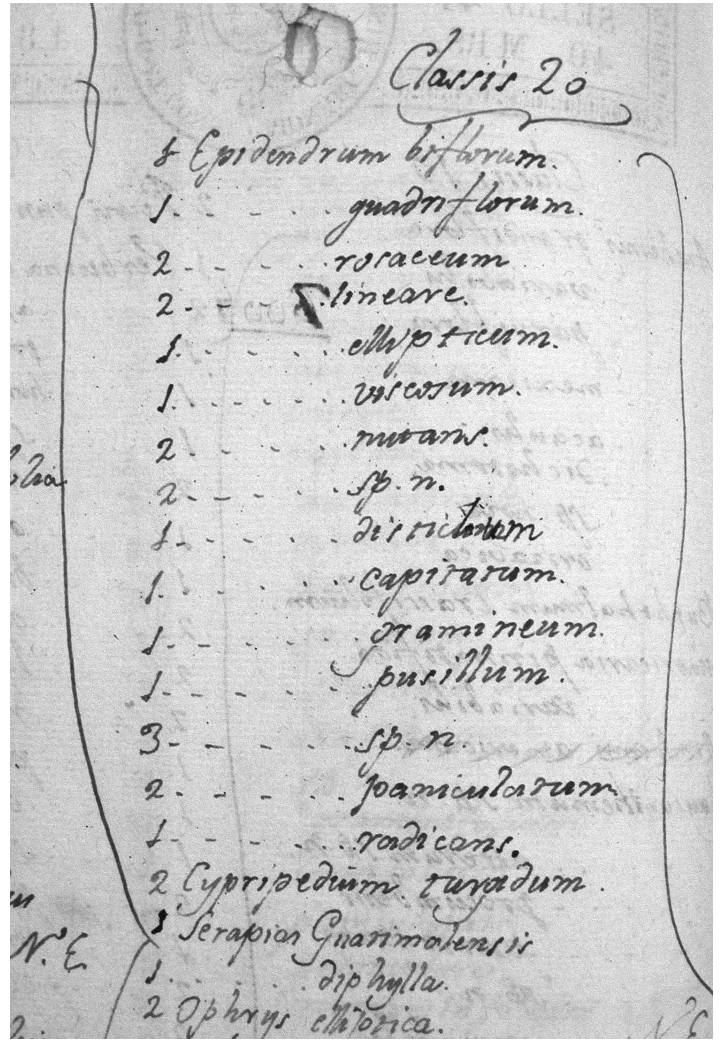

Fig. 1. Lista de especímenes del género Epidendrum vendidos por Pavón a Lambert. Entre ellos aparece por primera vez el epíteto radicans. Por cortesía del British Museum of Natural History.

dría un papel destacado en la expedición junto a Sessé: el criollo José Mariano Mociño. Desde 1787 Sessé había iniciado las actividades de campo, que se prolongaron inicialmente hasta 1794. En diversos viajes exploratorios, a los que se unió Mociño a partir de 1790, los expedicionarios exploraron toda la zona central de México, incluyendo las costas del Pacífico y del Golfo de México. Otros itinerarios llevaron a miembros de la expedición hasta el norte de México, California y la costa del Pacífico norte canadiense. El plazo fijado para la finalización de la expedición expiraba en octubre de 1794. En vista de que no habían podido explorarse aún los territorios de la franja sur del Virreinato - la Raya de Guatemala Sessé solicitó una ampliación que fue aprobada por Real Orden de Carlos IV el 15 de setiembre de 1794. En ella se disponía que la expedición recorriese, en el término de dos años, el Reino de Guatemala y simultáneamente las Islas de Barlovento. Así, la expe- dición se dividió en dos y en mayo de 1795 un primer grupo, al mando de Sessé, embarcó en Veracruz para explorar las islas de Cuba, Santo Domingo y Puerto Rico. El segundo grupo, encabezado por Mociño, partió en junio del mismo año desde la ciudad de México en dirección sur. Después de detenerse largo tiempo en la capital guatemalteca, el grupo de Mociño llegó en 1797 a Cartago, Costa Rica, sitio que fue el más meridional alcanzado por la expedición. El plazo autorizado en la prórroga expiró y no fue sino hasta mayo de 1798 que Sessé regresó a la capital mexicana. Mociño hizo lo mismo en febrero de 1799. Nuevos obstáculos, fundamentalmente la guerra con Inglaterra, impidieron el regreso de los expedicionarios a España, que finalmente se produjo en 1803.

El material colectado por la expedición llegó a España en momentos de gran convulsión política. Gran parte del material (especialmente el herbario) quedó en manos de la "Oficina Botánica" que controlaba José Pavón, especialmente después de la muerte de Sessé en 1808 y el exilio forzoso de Mociño a Francia en 1813. Y fue precisamente Pavón quien, a partir de 1814, se dedicó a manejar las colecciones, vendiendo ejemplares del herbario de la Expedición Botánica de Nueva España y los duplicados de la Flora de Perú y Chile, dilapidando así los fondos que estaban bajo su custodia.

Entretanto, en Inglaterra, el acaudalado botánico Aylmer Bourke Lambert (1761-1842) era nombrado en 1788 como uno de los primeros miembros de la Linnean Society. Apasionado coleccionista, Lambert logró reunir una enorme biblioteca y un herbario que fue uno de los más importantes y diversos de su tiempo. No sabemos cómo se enteró Lambert de las andanzas de Pavón, pero sí sabemos que desde 1814 hasta 1825 Pavón le vendió más de 15000 especímenes botánicos y zoológicos que se encontraban en la "Ofícina Botánica" de Madrid.

Es durante esta relación comercial cuando, entre los ejemplares vendidos por Pavón a Lambert, aparece de nuevo el Epidendrum radicans. Pavón prepara, en 1822, una extensa lista de los ejemplares botánicos recién enviados a Lambert. Dicha lista se encuentra hoy día en los archivos del Natural History Museum de Londres. En una de las páginas de la lista, manuscrita por Pavón, se encuentran los ejemplares del género Epidendrum vendidos a Lambert (Fig. 1) y entre ellos aparece por primera vez el nombre de 


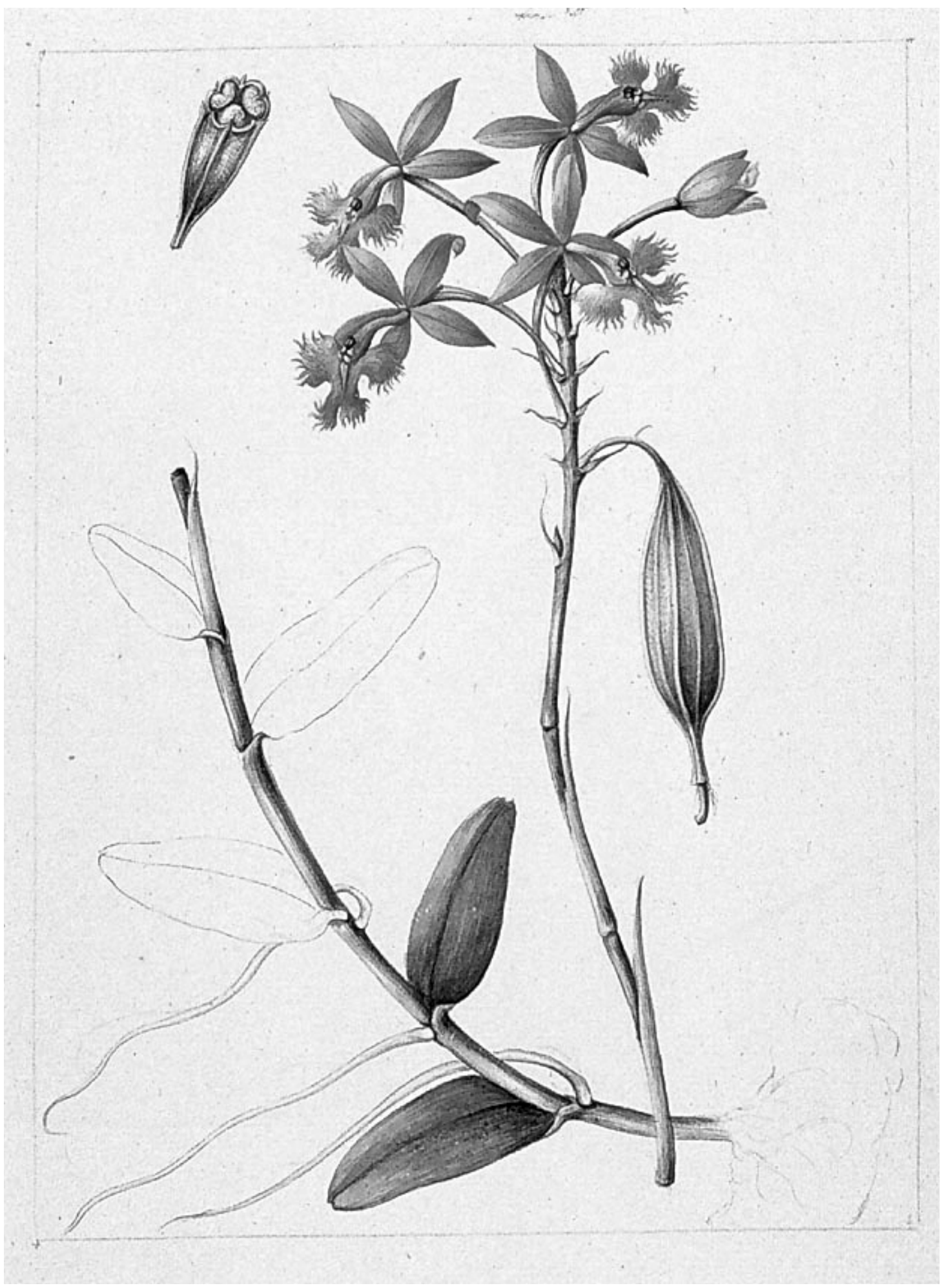

Fig. 2. La ilustración original de Epidendrum radicans en la "Colección Torner" de la expedición de Sessé y Mociño. 
Epidendrum radicans, un nombre que no tendría validez hasta que Lindley, en 1831, publicara su descripción con el epíteto dado por Pavón.

Generoso con sus amigos y colegas, Lambert siempre permitió que los científicos de su época utilizaran libremente su biblioteca y su herbario. Fue así como Lindley pudo estudiar e identificar muchos de los ejemplares que provenían de Madrid. A toda esta cadena de casualidades debemos la primera publicación y descripción del Epidendrum radicans (Fig. 2).

Esta historia no tiene un final feliz. Sessé en 1808 y Mociño en 1820 mueren sin ver realizados sus sueños de publicar las floras de México y Guatemala. Las 2000 ilustraciones de la Expedición Botánica a Nueva España, que Mociño había llevado consigo durante su exilio francés, desaparecen tras su muerte. En 1981 son descubiertas por el Hunt Institute for Botanical Documentation de Pittsburg, Pennsylvania, en la biblioteca particular de la familia Torner de Barcelona. El Hunt Institute las adquiere por la suma de 2000 pesetas por ilustración. Al igual que 160 años antes los ejemplares del herbario, las ilustraciones de la expedición de Sessé y Mociño marchan hacia el extranjero bajo la mirada complaciente del gobierno español.
Lambert muere en 1842 y su deseo de que su herbario se conservara intacto tras su muerte tampoco es cumplido. Sus colecciones se subastan en lotes separados y se dispersan por todo el mundo. La mayor parte de los materiales que Pavón había vendido a Lambert pasan al Museo de Historia Natural de Londres, donde todavía permanecen.

Pavón, por su parte, es finalmente obligado a rendir cuentas de sus actos en 1831 y tres años más tarde la Junta de Protección del Museo de Ciencias de Madrid le suspende de todo su sueldo. Triste guardián de los tesoros científicos llevados a España desde América por las expediciones botánicas de las últimas tres décadas del siglo XVIII, muere en desgracia en 1844.

Agradecimientos. A Gustavo Romero (Universidad de Harvard), Henry Oakeley (Royal Horticultural Society), Roy Vickery (Natural History Museum de Londres) y Mar González (Real Jardín Botánico de Madrid), por toda su ayuda y por brindar información y documentos de gran importancia. A Robert L. Dressler y Franco Pupulin, siempre generosos a la hora de compartir sus conocimientos. A Mary Noble McQuerry, esperando que nunca pierda su capacidad de encontrar libros y documentos, aunque no existan. A mi esposa Pilar, por todo su apoyo y toda su paciencia.

Carlos Ossenbach es arquitecto de profesión y orquideólogo aficionado. Desde 1996 mantiene el Orquideario 25 de Mayo en Sabanilla de Montes de Oca y es cofundador de la Fundación Charles H. Lankester. Sus dos intereses principales son la historia de la orquideología y la bibliografía sobre orquídeas, que se refleja en su "Guía Bibliográfica de las Orquídeas de Costa Rica" (en preparación). 